九州大学学術情報リポジトリ

Kyushu University Institutional Repository

\title{
Factors Influencing Consumer Willingness to Consume Genetically Modified Soybean Oil and Rice in China
}

Chen, Tinggui

College of Economics and Management, Shanghai Ocean University

Liu, Mingwei

College of Engineering Science and Technology, Shanghai Ocean University

Nanseki, Teruaki

Laboratory of Agricultural and Farm Management, Division of Agricultural and Resource

Economics, Department of Agricultural and Resource Economics, Faculty of Agriculture, Kyushu University

Li, Dongpo

Faculty of Agriculture, Kyushu University

他

https://doi.org/10.5109/1564103

出版情報: 九州大学大学院農学研究院紀要. 61 (1)，pp.195-203，2016-02-29. Faculty of Agriculture, Kyushu University

バージョン :

権利関係 : 


\title{
Factors Influencing Consumer Willingness to Consume Genetically Modified Soybean Oil and Rice in China
}

\author{
Tinggui CHEN ${ }^{1}$, Mingwei LIU ${ }^{2}$, Teruaki NANSEKI*, Dongpo LI ${ }^{3}$ and Miaomiao CHEN \\ Laboratory of Agricultural and Farm Management, Division of Agricultural and Resource Economics, \\ Department of Agricultural and Resource Economics, Faculty of Agriculture, \\ Kyushu University, Fukuoka 812-8581, Japan \\ (Received October 19, 2015 and accepted November 19, 2015)
}

\begin{abstract}
The objective of this paper is to study the factors influencing consumer willingness to consume (WTC) the genetically modified (GM) foods in the case of the GM soybean oil and the insect-resistant GM rice. The seemingly unrelated regression model was adopted and consumers in Shanghai city were surveyed.

The results show that consumer WTC GM soybean oil and GM rice is influenced by some factors that cannot be observed, however the observable factors make an obvious difference. The positive information has positive impact on consumers' WTC the GM soybean oil. The negative information predominates when the positive and negative information are simultaneously presented. The consumers' inherent awareness and safety evaluation of GM soybean oil has a significantly positive impact on the WTC. The impact of the negative publicity and consumers' attitude to compulsory labeling system is negative. Other factors significantly affect the WTC: gender, kid, professional status, income, reading of label information, evaluation of government regulation and purchasing frequency.
\end{abstract}

Key words: GM Soybean Oil, GM Rice, Information, Seemingly Unrelated Regression, WTC

\section{INTRODUCTION}

The introduction, research and application of transgenic technology have gone on for over 30 years in China, and during this period there have been both positive and negative views about the genetically modified foods. Supporters believe that GM foods are safe and more nutritious. GM crops produce a higher yield and an insect-resistant transgenic crop needs less agrochemical (Zhang, 2013; Huang, 2004). The Biotechnology Information Committee believes that GM crops are good for the environment by reducing the use of pesticides and herbicides, are conductive to social development by increasing yields and are good for farmers' health because of reduced exposure to the toxic substances.

However, many people question and even deny the safety of the GM foods (Lang, 2010; Gu, 2011). Several studies have shown that some mice's organs, immune system and nervous system are abnormal after eating the GM foods. GM crops are likely to pose potential threats to the land, water and biodiversity. In addition, the transgenic technology has been thought to be the way that the patent owners "seek the global food market position, permanently control human rations", and "promote food hegemony, trying to control other countries and even humankind" (Gu, 2011).

In China's edible oil market, soybean oil accounts for the largest portion. Over 85 percent of soybeans con-

\footnotetext{
College of Economics and Management, Shanghai Ocean University, P. R. China

${ }^{2}$ College of Engineering Science and Technology, Shanghai Ocean University, P. R. China

${ }^{3}$ Faculty of Agriculture, Kyushu University

* Corresponding author (E-mail: nanseki@agr.kyushu-u.ac.jp)
}

sumed in China are imported, and most are GM. China is the largest producer and consumer of rice in the world, and rice is the staple food of more than $65 \%$ of the people. Therefore, the production of rice is extremely important for China's food security and safety. In 2009, the insect-resistant transgenic rice, developed by Huazhong Agricultural University, obtained a security certificate to plant, and for human and animal consumption. The safety certificate expired and was reissued at the end of 2014. So far, commercial production has not been approved. However, a large quantity of GM rice has been reportedly to circulate on the market. In addition, rice products exported to EU were detected repeatedly to contain GM rice.

Many prior researches have engaged in studying the GM foods. Kikulwe et al. (2011), Qi and Zhou (2010), and Ghasemi et al. (2013) mainly focused on consumer perception of GM foods. Bukenya and Wright (2007), Depositario et al. (2009), Steur et al. (2012) studied the Willingness to Pay (WTP) of GM foods. Some other researchers analyzed the factors influencing consumers' awareness and WTP through econometric model. The main study objects include GM vegetables (McComas et al., 2014; Curtis and Moeltner, 2007), GM fruits (Ma and $\mathrm{Gu}, 2011$; Kikulwe et al., 2011), GM grains and other agricultural products (Depositario et al., 2009; Steur et $a l ., 2012$ ) and the processed food containing GM raw materials (Curtis and Moeltner, 2007; Zhong and Chen, 2008; Chen et al., 2013).

Based on the above reviews, this paper chooses the transgenic soybean oil and genetically modified rice as the research objects, adopting the seemingly unrelated regression (SUR) model to comparatively analyze the factors influencing consumer WTC different kinds of GM foods. Particularly, this paper focuses on the role of 
information as the impact factor, discusses whether the impact factors unobserved for different GM foods are in the same performance or not. In the following sections, the second part is the analytical framework, hypothesis and method; the third part is the data sources and variable description; the fourth part is an analysis of the factors impacting consumers' willingness to consume the GM soybean oil and the GM rice, and the last part is conclusions and recommendations.

\section{ANALYTICAL FRAMEWORK, HYPOTHESIS AND METHOD}

\section{Analytical Framework}

Consumer behavior is decided by both external and internal factors. External factors mainly include culture, subculture, population, environment, social status, reference groups, family and marketing activities. Internal factors include perception, learning, memory, motivation, personality, mood and attitude (Hawkins and Mothersbaugh, 2011). Information has been regarded as one of the most important variable in the consumer purchase behavior model and different researchers have different answers about information's influence. However, researchers have reached a consensus on the path of forming consumer attitude toward foods or services, namely the information comes into being awareness then awareness forms attitude. At the same time, the information may also form attitude directly (Luo, 2010). Therefore, the relationship between awareness, attitude and information may be described as "consumers' awareness comes from learning relative knowledge (information) and then forming their own attitude". Consumer attitude is shaped by their knowledge and new information from various sources. Attitude is the important factor affecting people's behavior in theory of planned behavior (TPB).

Involvement mainly refers degree of correlation between consumers and the products. Consumer product involvement is defined as "The product's level of concern and attention for consumers" (Laurent and Kapferer, 1985). Involvement can be regarded as the motivation to process the information. The stronger the link between the individuals' need, goals, values and product knowledge, the higher the consumers' attention to the product information is. According to Brady and Brady (2003), consumers' familiarity with the product often represents how they master information, and the familiarity can often be measured by purchase frequency. Accordingly, consumers' concern and previous purchase frequency will affect their processing of information and ultimately their WTC.

In addition, Nayga (1996) found that social-demographic factors would affect consumers' information acquisition and ultimately influence consumers' attitude and behavior. Therefore, consumers' demographic characteristics such as gender, age, education, family characteristics such as family members, and economic characteristics such as income are introduced in this paper as the control variables affecting consumer WTC GM foods.
Based on the above analysis, the framework of this paper is shown in Fig. 1.

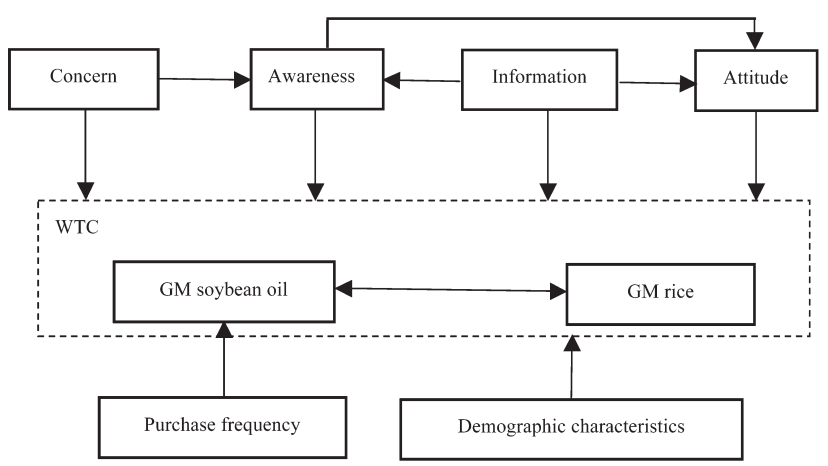

Fig. 1. Analytical framework of consumers' WTC GM foods.

\section{Hypothesis}

From Fig. 1, we can see that information not only can affect the WTC through awareness and attitude, but can also affect the WTC directly. Zhong and Ding (2004) pointed out that consumers are more sensitive to negative information than positive information. Robin et al. (2011) surveyed the adult consumers in the mid-Atlantic of the U.S. by experimental method to study the impact of media information on consumer behavior. The results showed that the positive and negative information have influence on consumer WTP, and the effect of negative information is greater. Ma and Gu (2011), taking the transgenic and non-GM apple for example, applied the method of experimental economics to get the results: consumers preferred the non-GM foods when they got information, but they prefer GM foods when without information. Depositario et al. (2009) analyzed the influence of information on the students' WTP for the golden rice in the University of the Philippines by a uniform-price auction and OLS regression. The findings showed that the mean WTP bids are highest under positive information, followed by no information, negative information, and unexpectedly lowest with two-side information. Furthermore, there is a minor difference in WTP with respect to the reference price between positive information and no information and the marginal effect on WTP of positive information is minimal. According to the above discussion the following hypothesis is put forward:

Hypothesis 1: The information affects the consumers' WTC. The positive information has a positive influence, the negative information has a negative influence and makes a greater degree of influence.

A lot of literature has shown that consumers' knowledge or awareness affects significantly their WTC GM foods. The study of McComas et al. (2014) found that the consumers' objective knowledge negatively affects their support for GM foods, but the influence of subjective information is positive. Steur et al. (2012) found that consumers' objective GM knowledge has a positive influence on the choice of nutritional GM foods. Ghasemi et al. (2013) selected ten statements about GM crops, GM foods and transgenic technology to measure 
consumer awareness of GM foods. The result revealed that high awareness does not lead to high probability of purchasing GM foods. This paper chooses "whether the consumers have the relevant knowledge on agriculture, food or medical treatment $(k n o)$ )" (namely, the inherent awareness) and "their cognizance of the questions in the questionnaire (kno1, kno2, kno3 and kno4)" (namely, the consumers' knowledge on some related regulation or the food safety incidents) as the variables for measuring the awareness. The intrinsic awareness forms after accumulation over a long period of time and becomes solidified into the consumers' inner attributes. The behavior of the consumers with higher inherent awareness is more rational or autonomous. However, the WTC of the consumers is affected by not only the inherent awareness but also the current events. If the awareness is neutral and limited, then the different awareness forms a different attitude or intention. Based on the above discussion the following hypothesis is put forward: Hypothesis 2: The consumer awareness has an effect on the WTC, but the influence is different because of the differences in knowledge of GM foods and the uncertainty of transgenic technology risk.

Luo (2010) takes "the necessity of using safety food labeling" as the variable measuring "attitude". The consumers are willing to buy the non-GM foods under the compulsory identification policy, but prefer GM foods under voluntary labeling policy ( $\mathrm{Ma}$ and $\mathrm{Gu}, 2011$ ). Although China implements compulsory labeling system of GM foods, there are still some questions such as small and inconspicuous logo and font, as well as unlabeled genetic ingredients, so that many consumers have no idea whether the foods are GM or not. The consumers who think the compulsory labeling system is necessary want the right to know and choose autonomously. They are not satisfied with the labeling and are not willing to buy the GM foods.

Ma and Gu (2011) have also shown that the safer consumers think GM foods are, the more they prefer them. Guo et al. (2013) found that the perceived risk directly reduces consumer purchase intention of GM foods. McComas et al. (2014) found that the more consumers perceive the risk of GM foods for humans and the environment, the less they are willing to buy GM foods. The consumers who think transgenic soybean oil is safe believe that the GM foods pose no safety risk or health threat, namely their perceived risk is low, so that their WTC is high. This paper uses "consumers' attitude towards implementing compulsory labeling system of GM foods (label)" and "the safety evaluation of GM soybean oil (segmoil)" as the variables measuring attitude. Based on the above discussion the following hypothesis is put forward:

Hypothesis 3: The consumers' attitude toward labeling affects the WTC negatively, and the impact on the safety evaluation of GM soybean oil is positive.

More than $90 \%$ of the corns and soybeans in the United States are reportedly GM crop. About 20\% of the corn and $40 \%$ of the soybeans are exported. More than $90 \%$ of the soybean oil in China is made from the imported GM soybeans. The insect-resistant transgenic rice still isn't allowed to be commercially produced even though the safety certificate has been issued several times. However, the GM ingredients were reportedly detected in the rice products. Soybean oil and rice are indispensable foods in China. Both GM soybean oil and GM rice are classified as GM foods, so the consumer WTC these two kinds of foods may be a positive correlation. However, they are also different types of foods. The GM soybean oil has already been marketed for more than ten years, but the commercial production of the GM rice is still in dispute. So the influence factors may be different (Zhong and Ding, 2004; Bukenya and Wright, 2007, Depositario et al., 2009, Kikulwe et al., 2011). Based on the above discussion the following hypothesis is put forward:

Hypothesis 4: The consumers' WTC the GM soybean oil and GM rice is positively correlated, but the factors and degree of influence are significantly different.

\section{Method}

Logistic model (Bukenya and Wright, 2007; Ma and Gu, 2011; Chen et al., 2013; Qi and Zhou, 2010) and structural Equation model (Ghasemi et al., 2013; Guo et al., 2013; Amin et al., 2014) are most used to study the factors impacting the consumers' WTC the GM foods. Furthermore, Generalized Linear model (McComas et al., 2014); Probit model (Curtis and Moeltner, 2007); Double-hurdle model (Steur et al., 2012) and DoubleFactors Probability Selection model (Chen et al., 2004) are also adopted.

Based on the Fig. 1 and the above analysis, we assume that the WTC GM foods and the explanatory variables are linear. So the WTC can be described as:

$$
\begin{aligned}
& \text { wtcgmoil }=\alpha X_{i}+\varepsilon_{1 \mathrm{i}} \\
& \text { wtcgmrice }=\beta Z_{i}+\varepsilon_{2 i}
\end{aligned}
$$

The wtcgmoil in Eq. (1) and the wtcgmrice in Eq. (2) represent the consumers' WTC the GM soybean oil and GM rice respectively. Accordingly to the Fig. 1, the wtcgmoil and the wtcgmrice are affected by most of the common factors. The GM soybean oil has already been marketed, so it may be affected by some other factors. The $X_{\mathrm{i}}$ includes the information we provided in the questionnaire, the consumers' awareness, attitudes, concern, demographic characteristics, consumers' purchase of soybean oil and GM soybean oil. The $Z_{i}$ includes the information we provided in the questionnaire, the consumers' awareness, attitudes, concern and demographic characteristics. The $\alpha$ and $\beta$ are parameters to be estimated, and the symbol of $\varepsilon_{1}$ and $\varepsilon_{2}$ are random error terms.

We assume the mean of $\varepsilon_{1}$ and $\varepsilon_{2}$ is zero, that is to say:

$\mathrm{E}(\varepsilon \mid X, Z)=0$

In Eq. (3), $\varepsilon=\left[\varepsilon_{1}{ }^{\prime}, \varepsilon_{2}^{\prime}\right]^{\prime}$, the consumers' WTC the GM soybean oil and GM rice is affected by most of the common factors and their analytical structures are simi- 
lar, so the error terms in Equations (1) and (2) are correlated. Then we can get:

$$
\mathrm{E}\left(\varepsilon_{1} \varepsilon_{2}^{\prime} \mid X, Z\right)=\Omega \neq 0
$$

Based on the assumption in Equations (3) and (4), Equations (1) and (2) are correlated because their error terms are correlated, and the independent variables in the equations are not exactly the same. This means that the results will be biased and inconsistent when we estimate the each equation separately.

Based on the above analysis, this paper will apply the SUR model to estimate the factors impacting consumers' WTC the GM soybean oil and GM rice at the same time. The specific method is the generalized least square method. According to the strength and significance of the correlation of the error terms in the estimated results, we can know whether Eq. (4) is right. We can determine further the correlation of the variables in each equation through the sign of the correlation coefficient (Quan et al., 2011).

\section{DATA AND VARIABLES}

\section{Data Sources and Sample Characteristics}

The data was collected by a survey in Shanghai, China from May to June, 2014. The respondents are the urban consumers in Shanghai. On one hand, Shanghai is the center of China's economy and finance and is the most international city in China, so it is easier for the consumers to access cutting-edge technology and information such as the GM technology. On the other hand, rice is the staple food of the citizens in Shanghai, so its safety is related to everyone's vital interests. Therefore, choosing the consumers in Shanghai as the respondents is rational and necessary. We randomly selected the trained students in Shanghai from Shanghai Ocean University as investigators and each student was asked to survey less than ten respondents from their parents, relatives or their parents' colleagues. Altogether 473 questionnaires were issued and 403 were valid, with an effective rate of $85 \%$.

There are more female respondents than the male respondents, over $86 \%$ of the people are 20 to 59 years old, and nearly $70 \%$ are married. Almost two-thirds of the respondents have attended college and half of them work in the enterprises. The monthly income (RMB) in most of the households is under 14999 yuan, and less than $6 \%$ of household is above 20000 yuan. Overall, the distribution of the samples is reasonable and representative.

In addition, the main cooking oil used in more than half (52\%) of the families is the soybean oil, and a third choose blended oil as their main cooking oil. Most of the respondents (82\%) are familiar with GM soybean, and a third is familiar with GM rice. Over half of the respondents are the main decision makers to buy food.

\section{Variable Definition}

Due to the fact that GM rice hasn't been permitted for commercial production, we cannot get the market price. Therefore, we selected "the level of the consumers' agreement to the commercial production of the GM rice" as the variable measuring the consumers' WTC the GM rice. The values are 1, 2 and 3 from low to high in accordance with the level of the agreement. The questionnaires were set as A, B, C and D, which represented four types of different information on the GM rice. There is the positive information in A, the negative information in $\mathrm{B}$, the both positive and negative information in $\mathrm{C}$, and no information in $\mathrm{D}$. Among the valid questionnaires, 101 are A; 89 are B; 106 are C and 107 are D. The representative information comes from the comments of some authoritative experts and scholars in the field whose published work can be found in books, magazines or news. The variable definition and summary statistics are shown in Table1.

\section{FACTORS AFFECTING THE CONSUMERS' WTC}

\section{Purchase Intention and Purchase Behavior}

Sometimes, the customer's WTC and their behavior are in conflict (Chen et al., 2013). Therefore, it is necessary to analyze the relationship between the purchase intention and the purchase behavior. This paper analyzes the consumers' WTC the GM soybean oil and the previous purchase frequency of the GM soybean oil, without the samples that choose "unaware". Table 2 and Table 3 show the relationship of the purchase intention and the purchase behavior. Both of the Chi-square tests $(\mathrm{P}<0.01)$ are effective in the two tables. Among the consumers who are willing to buy the non-GM soybean oil, less than $6.5 \%$ frequently buy the GM soybean oil and more than half never buy the GM soybean oil (Table 2). $80 \%$ of the consumers who are willing to buy the GM soybean oil have previously bought the GM soybean oil, and over one fifth chose "frequently buying the GM soybean oil", much higher than the overall level. At the same time, the proportion of the consumers who chose "sometimes buying the GM soybean oil" increases as their WTC the GM soybean oil increasing. More than half of the respondents choosing "not sure" have previously bought the GM soybean oil.

In the table 3 , nearly $90 \%$ of the consumers willing to buy the non-GM soybean oil have previously purchased non-GM soybean oil, in which $43.7 \%$ chose "buy often the non-GM soybean oil". However, the proportion only accounts for $28 \%$ among the consumers who are willing to buy the GM soybean oil, lower than the overall level. As a whole, the purchase intention and the purchase behavior are basically consistent. Therefore, it is meaningful to study the factors affecting the consumers' purchase intention.

\section{Factors Affecting WTC}

Based on the variables listed in Table 1 and the model in Equations (1) and (2), we apply the SUR to estimate the factors affecting WTC. The results are shown in Table 4. The overall fitting effect of the model is good. The two equations are significant at the $1 \%$ statistics level, which indicates, as a whole, the selected 
Table 1. Variable definition $(\mathrm{n}=403)$

\begin{tabular}{|c|c|c|c|}
\hline Variable Definition & Variable Value & Mean & Std. D. \\
\hline \multicolumn{4}{|l|}{ Explained Variable } \\
\hline WTC GM soybean oil (wtcgmoil) & buy non-gm oil=1, don't care $=2$, buy gm oil $=3$ & 1.50 & 0.73 \\
\hline $\begin{array}{l}\text { Consumer agreement to the commercial production of the GM rice } \\
\text { (wtcgmrice) }\end{array}$ & 1,2 and 3 in accordance with the agreement & 2.16 & 0.67 \\
\hline \multicolumn{4}{|l|}{ Explanatory Variable } \\
\hline Positive information (inf1) & no $=0$, yes $=1$ & 0.25 & 0.44 \\
\hline Negative information (inf2) & no $=0$, yes $=1$ & 0.22 & 0.42 \\
\hline Both positive and negative information (inf3) & no $=0$, yes $=1$ & 0.26 & 0.44 \\
\hline No information (inf4) & no $=0$, yes $=1$ & 0.27 & 0.44 \\
\hline Knowledge of agriculture, food or medical (kno) & unknown $=0$, known $=1$ & 0.20 & 0.40 \\
\hline The use of GM technology is prohibited in organic production (kno1) & unknown $=0$, known $=1$ & 0.39 & 0.49 \\
\hline $\begin{array}{l}\text { Only the GM cotton and papaya are allowed commercial production in } \\
\text { China (kno2) }\end{array}$ & unknown $=0$, known $=1$ & 0.19 & 0.40 \\
\hline $\begin{array}{l}\text { The survey on the GM foods done by YongyuanCui in December } 2013 \text { in } \\
\text { USA (kno3) }\end{array}$ & unknown $=0$, known $=1$ & 0.43 & 0.50 \\
\hline The debate about the GM foods on the "two session" in 2014 (kno4) & unknown $=0$, known $=1$ & 0.42 & 0.49 \\
\hline $\begin{array}{l}\text { Consumers' attitude towards compulsory labeling system of the GM } \\
\text { foods(label) }\end{array}$ & others $=0$, necessary $=1$ & 0.90 & 0.30 \\
\hline Safety evaluation of the GM soybean oil (segmoil) & unsafe $=1$, hard to say $=2$, safe $=3$ & 1.80 & 0.83 \\
\hline Concern about the GM foods (concerngmf) & $\begin{array}{l}\text { totally unconcerned }=1 \text {, unconcerned }=2 \text {, } \\
\text { concerned }=3 \text {, very concerned }=4\end{array}$ & 2.85 & 0.92 \\
\hline Seeking food information before buying (infs) & never $=1$, sometimes $=2$, often $=3$, always $=4$ & 2.17 & 0.72 \\
\hline Reading the information on the food packaging (infr) & never $=1$, sometimes $=2$, often $=3$, always $=4$ & 2.70 & 0.77 \\
\hline Evaluation of the governmental regulation (evagr) & very bad $=1$, bad $=2$, good $=3$, very good $=4$ & 2.04 & 0.68 \\
\hline Main cooking oil is soybean oil (soybean oil) & no $=0$, yes $=1$ & 0.54 & 0.50 \\
\hline Never bought GM soybean oil (ppgmoil) & others $=0$, never $=1$ & 0.42 & 0.49 \\
\hline Sometimes bought GM soybean oil (ppgmoil2) & others $=0$, sometimes $=1$ & 0.38 & 0.49 \\
\hline Often bought GM soybean oil (ppgmoil3) & others $=0$, often $=1$ & 0.07 & 0.26 \\
\hline Unaware whether bought GM soybean oil (unaware) & others $=0$, unaware $=1$ & 0.13 & 0.34 \\
\hline Gender & female $=0$, male $=1$ & 0.43 & 0.50 \\
\hline Age (age0) & others $=0$, under 20 years old $=1$ & 0.06 & 0.24 \\
\hline age1 & others $=0,20-39$ years old $=1$ & 0.49 & 0.50 \\
\hline age2 & others $=0,40-59$ years old $=1$ & 0.37 & 0.48 \\
\hline age3 & others $=0,60$ years old or above $=1$ & 0.08 & 0.27 \\
\hline If there are kids below 12 years old (kid) & no $=0$, yes $=1$ & 0.33 & 0.47 \\
\hline If there are adults over 60 years old (old) & no $=0$, yes $=1$ & 0.56 & 0.50 \\
\hline Education (edu0) & others $=0$, middle school or below $=1$ & 0.14 & 0.35 \\
\hline edu1 & others $=0$, high school $=1$ & 0.23 & 0.42 \\
\hline edu2 & others $=0$, college or above $=1$ & 0.63 & 0.48 \\
\hline Work in a government agency, university, or research institution (work0) & no $=0$, yes $=1$ & 0.14 & 0.35 \\
\hline Work in the private sector (work1) & no $=0$, yes $=1$ & 0.51 & 0.50 \\
\hline Self-employed entrepreneur (work2) & no $=0$, yes $=1$ & 0.09 & 0.29 \\
\hline Student (work3) & no $=0$, yes $=1$ & 0.16 & 0.36 \\
\hline Unemployed (work4) & no $=0$, yes $=1$ & 0.10 & 0.30 \\
\hline Monthly household income (inc0) & others $=0,<5000$ yuan $=1$ & 0.29 & 0.45 \\
\hline inc1 & others $=0,5000-9999$ yuan $=1$ & 0.35 & 0.48 \\
\hline inc2 & others $=0,10000-14999$ yuan $=1$ & 0.22 & 0.42 \\
\hline inc3 & others $=0, \geq 15000$ yuan $=1$ & 0.14 & 0.34 \\
\hline
\end{tabular}


Table 2. Consumer purchase intention and purchase behavior for the GM soybean oil

\begin{tabular}{lccccc}
\hline \multirow{2}{*}{$\begin{array}{c}\text { Previous purchase frequency } \\
\text { for the GM soybean oil }\end{array}$} & Item & \multicolumn{4}{c}{ WTC the GM soybean oil } \\
\cline { 3 - 6 } & & Buy non-GM oil & Do not care & Buy GM oil & Total \\
\hline \multirow{2}{*}{ Never } & Count & 126 & 32 & 10 & 168 \\
& Percentage & $54.31 \%$ & $46.38 \%$ & $20.83 \%$ & $48.14 \%$ \\
\hline \multirow{2}{*}{ Sometimes } & Count & 91 & 33 & 28 & 152 \\
& Percentage & $39.22 \%$ & $47.83 \%$ & $58.33 \%$ & $43.55 \%$ \\
\hline \multirow{2}{*}{ Often } & Count & 15 & 4 & 10 & 29 \\
& Percentage & $6.47 \%$ & $5.80 \%$ & $20.83 \%$ & $8.31 \%$ \\
\hline \multirow{2}{*}{ Total } & Count & 232 & 69 & 48 & 349 \\
& Percentage & $100 \%$ & $100 \%$ & $100 \%$ & $100 \%$ \\
\hline
\end{tabular}

Note: Chi-square test $\mathrm{p}$ value $=0.000$

Table 3. Purchase intention and purchase behavior for the non-GM soybean oil

\begin{tabular}{lccccc}
\hline \multirow{2}{*}{$\begin{array}{c}\text { Previous purchase frequency } \\
\text { for the non-GM soybean oil }\end{array}$} & Item & \multicolumn{4}{c}{ WTC the GM soybean oil } \\
\cline { 3 - 6 } Never & & Buy non-GM oil & Do not care & Buy GM oil & Total \\
\hline \multirow{2}{*}{ Sometimes } & Count & 26 & 15 & 8 & 49 \\
& Percentage & $10.92 \%$ & $20.27 \%$ & $16 \%$ & $13.54 \%$ \\
\hline \multirow{2}{*}{ Often } & Count & 108 & 44 & 28 & 180 \\
& Percentage & $45.38 \%$ & $59.46 \%$ & $56 \%$ & $49.72 \%$ \\
\hline \multirow{2}{*}{ Total } & Count & 104 & 15 & 14 & 133 \\
& Percentage & $43.70 \%$ & $20.27 \%$ & $28 \%$ & $36.74 \%$ \\
\hline
\end{tabular}

Note: Chi-square test $\mathrm{p}$ value $=0.003$

variables have significant influence on consumers' WTC.

Compared to no information, the positive information (inf1) affects significantly the consumers' WTC the GM soybean oil. When the positive and negative information are provided, the influence is negative. The possible reason is that the consumers will believe or focus on the negative information when they get both the positive and negative information. Although the influence of the negative information is not significant, the sign is negative. However, the information doesn't affect significantly the WTC the GM rice. The probable reason is that the GM rice has not been sold on the market, the consumers' perception about it is low and they selectively accept the information provided. Hypothesis 1 is verified to some extent.

"Whether or not the consumers have relevant knowledge on agriculture, food or medicine (kno)" (namely, the inherent awareness) affects positively the WTC the two types of GM foods. It shows that the consumers whose inherent awareness is high do not reject the GM foods. Therefore, it is important for the developing GM industry to improve the consumers' inherent awareness. The impact of kno1 and kno2 is not significant. Since their signs are opposite, we can see the influence of some regulations about the GM foods has no obvious regularity. "The survey on the GM foods done by YongyuanCui December 2013 in the United States (kno3)" negatively impacts the consumers' WTC the GM foods. YongyuanCui is an opponent of the GM foods, so his survey has a negative effect. Hypothesis 2 is verified to some extent.
"The consumers' attitude towards implementing compulsory labeling system of GM foods (label)" affects the WTC negatively and the influence of "the safety evaluation of GM soybean oil (segmoil)" is positive with 1\% significance. So Hypothesis 3 is verified.

The greater the consumers' concern about the GM foods (concerngmf), the less they are willing to consume the GM soybean oil. It may be caused by the accidents or reports about GM foods. The negative coefficient of "reading the information in the food packaging (infr)" shows that the more the consumers read the information in the food packaging, the less they consume the GM rice. It illustrates the importance of the consumers' right to know. The higher the consumers' evaluation of the effect of the government regulation is, the more they trust the safety of the GM rice, and the stronger their WTC is.

In the factors of the demographic characteristic, the impact of gender, kid, work and income is significant. Except for kid and work0, there is a remarkable difference in the effect of other independent variables on the two dependent variables. Men show positive WTC, and the families whose children are younger than the age of 12 aren't willing to consume the GM foods. Compared to the unemployed consumers, the consumers who work in a government agency, university or research institution (work0) are not willing to buy the GM foods. The students are unwilling to eat the GM soybean oil. The highincome groups show more negative WTC than the lowincome consumers, which may be because the highincome consumers do not care about the price advan- 
Table 4. Regression results of the SUR model $(n=403)$

\begin{tabular}{|c|c|c|c|c|c|}
\hline \multirow{2}{*}{ Factor } & \multirow{2}{*}{$\begin{array}{l}\text { Independent } \\
\text { variable }\end{array}$} & \multicolumn{2}{|c|}{$\begin{array}{l}\text { WTC the GM soybean oil } \\
\text { (wtcgmoil) }\end{array}$} & \multicolumn{2}{|c|}{$\begin{array}{l}\text { WTC the GM rice } \\
\text { (wtcgmrice) }\end{array}$} \\
\hline & & Coefficient & Std. Error & Coefficient & Std. Error \\
\hline \multirow[t]{2}{*}{ Information } & inf2 & -0.014 & 0.093 & 0.063 & 0.082 \\
\hline & inf3 & $-0.153 *$ & 0.089 & -0.02 & 0.078 \\
\hline \multirow{3}{*}{ Awareness } & kno1 & -0.052 & 0.069 & 0.057 & 0.061 \\
\hline & kno2 & 0.070 & 0.084 & -0.023 & 0.075 \\
\hline & kno3 & $-0.161 * * *$ & 0.072 & $-0.167 * * *$ & 0.063 \\
\hline Concern & Concerngmf & $-0.100 * * *$ & 0.038 & 0 & 0.034 \\
\hline \multirow{2}{*}{ Information seeking and reading } & Infs & 0.054 & 0.050 & -0.062 & 0.044 \\
\hline & Infr & 0.054 & 0.047 & $-0.096 * *$ & 0.042 \\
\hline Evaluation of regulation & Evagr & -0.003 & 0.049 & $0.101 * *$ & 0.043 \\
\hline \multirow[t]{2}{*}{ Consumption of the soybean oil } & Soybean oil & $-0.164 * *$ & 0.066 & - & - \\
\hline & ppgmoil1 & $-0.287 * * *$ & 0.103 & - & - \\
\hline \multirow[t]{4}{*}{ Purchase frequency } & ppgmoil2 & -0.154 & 0.102 & - & - \\
\hline & Kid & $-0.136 *$ & 0.074 & $-0.110 *$ & 0.065 \\
\hline & Old & -0.085 & 0.067 & 0.053 & 0.059 \\
\hline & edu1 & -0.097 & 0.111 & -0.014 & 0.098 \\
\hline \multirow[t]{8}{*}{ Demographic characteristics } & edu2 & 0.005 & 0.112 & -0.002 & 0.099 \\
\hline & work0 & $-0.329 *$ & 0.155 & $-0.226 *$ & 0.137 \\
\hline & work1 & -0.199 & 0.131 & -0.153 & 0.115 \\
\hline & work2 & 0.003 & 0.156 & -0.131 & 0.138 \\
\hline & work3 & $-0.288 *$ & 0.166 & -0.15 & 0.147 \\
\hline & inc1 & 0.010 & 0.084 & -0.104 & 0.075 \\
\hline & inc2 & 0.146 & 0.096 & 0.014 & 0.085 \\
\hline & inc3 & 0.029 & 0.111 & $-0.169 *$ & 0.098 \\
\hline Constant term & _cons & $2.079 * * *$ & 0.303 & $2.068 * * *$ & 0.259 \\
\hline \multicolumn{2}{|l|}{ Chi-square statistics } & \multicolumn{2}{|c|}{186.8} & \multicolumn{2}{|c|}{224.31} \\
\hline \multicolumn{2}{|l|}{ Chi-square $p$ value } & \multicolumn{2}{|c|}{0.000} & \multicolumn{2}{|c|}{0.000} \\
\hline \multicolumn{2}{|l|}{ Correlation coefficient of error terms } & \multicolumn{4}{|c|}{$\rho_{12}=0.099 * *$} \\
\hline
\end{tabular}

Note: ***,*** denote $10 \%, 5 \%$, and $1 \%$ significance, respectively.

tage of the GM rice. The consumers whose main cooking oil is the soybean oil are willing to choose the non-GM soybean oil.

The correlation coefficient of the error terms in Table 4 shows that the consumers' WTC the GM soybean oil and the GM rice is significantly positively correlated. Overall, the unobservable error factors influence the consumers' WTC the GM soybean oil and the GM rice in the same direction. This indicates that the consumers want neither GM soybean oil nor GM rice. Therefore the study shows that consumers don't want GM food at all. According to the above analysis, we can see that the impact of the awareness, attitude, if there being kids younger than 12 years old and working in the govern- 
ment agency, university or research institution on the WTC the GM soybean oil and the GM rice is the same. However, the effect of information, reading the food packaging, the safety evaluation of the GM soybean oil, gender and income has significant difference. It verifies Hypothesis 4.

\section{CONCLUSIONS AND RECOMMENDATIONS}

The paper uses the examples of GM soybean oil and the GM rice to study the consumer WTC GM foods and analyze the factors affecting Shanghai consumers' WTC the two kinds of GM foods with the Seemingly Unrelated Regression model. The conclusions are as follows: Firstly, the consumer's WTC the GM soybean oil and the GM rice are significantly and positively correlated, but the influencing factors differ significantly. Secondly, the positive information has a positive impact on consumers' WTC the GM soybean oil, and the negative information predominates when both positive and negative information are simultaneously presented. Thirdly, the consumers' inherent awareness has remarkable positive effect on their WTC and the influence of negative events is negative. Fourthly, the impact of the attitude toward compulsory labeling system is negative, and the safety evaluation of the GM soybean oil positively affects the WTC. Finally, gender, kid, professional status, income, reading of label information, evaluation of government regulation and purchasing frequency significantly affect the WTC.

According to the above conclusions, we make the following recommendations: Firstly, the information providers should diffuse in a timely manner the real and reliable food information and objective publicity to improve consumers' inherent awareness, so that they may make a rational and right choice according to their own judgment when the food safety events happen. Secondly, government departments should continue strengthening to standardize the market of the GM foods, define the labeling system and ensure it to be carried out according to the standards, because the consumers have the right to know and the freedom to choose. The regulation directly affects the consumers' trust and then impacts the consumer behavior. Finally, since the consumer WTC the GM soybean oil and the GM rice is significantly positively correlated and the rice (as the staple food) is universal, the enterprises which produce the GM foods should work to change firstly the consumers' attitude and formulate the corresponding marketing strategies according to the differences between the factors influencing the consumers' WTC the different types of the GM foods.

\section{ACKNOWLEDGEMENT}

This research is supported by Shanghai Pujiang Program, and the fund supplied by College of Economics and Management, Shanghai Ocean University.

\section{REFERENCES}

Amin L., Azad M.A.K., Gausmian M. H. and Z. Faizah 2014 Determinants of Public Attitudes to Genetically Modified Salmon. Plos One, 9(1): 1-14

Brady, J. T. and P. L. Brady 2003 Consumers and Genetically Modified Foods. Journal of Family and Consumer Sciences, 95: 5

Bukenya J.O. and N.R. Wright 2007 Determinants of Consumer Attitudes and Purchase Intentions With Regard to Genetically Modified Tomatoes. Agribusiness, 23(1): 117-130

Chen C., C. Y. Shi, J. T. Zhan and X. Y. Lv 2013 Analysis on the Bias between Statement Preferences and Purchase Behavior Regarding Genetically Modified Foods: Based on Edible Oil Consumption of Urban Residents'. Issues in Agricultural Economy, 34(6): 82-88

Chen K., M. J. Shi and G. Hailu 2004 Willingness to Pay for NonGenetically Modified Vegetable Oil in China. Journal of Zhejiang University (Humanities and Social Science), 34: $53-61$

Curtis K.R., and K. Moeltner 2007 The Effect of Consumer Risk Perceptions on the Propensity to Purchase Genetically Modified Foods in Romania. Agribusiness, 23(2): 263-278

Depositario, D. P. T., R. M .Jr. Nayga, X. Wu and T.P. Laude 2009 Effects of Information on Consumers' Willingness to Pay for Golden Rice, Asian Economics Journal, 23(4): 457-476

Dillaway R., K. D. Messer, J. C. Bernard and H. M. Kaiser 2011 Do Consumer Responses to Media Food Safety Information? Applied Economic Perspectives and Policy, 33(3): 363-383

Ghasemi S., E. Karami and H. Azadi 2013 Knowledge, Attitudes and Behavioral Intentions of Agricultural Professionals toward Genetically Modified (GM) Foods: A Case Study in Southwest Iran. Sci. Eng. Ethics, 19: 1201-1227

Gu X. L. 2011 Transgenic War: China's Food Safety Battle in the 21th Century. Intellectual Property Press, Beijing

Guo J., X. H. Wu and W. M. Ye 2013 The Empirical Research on Chinese Consumer Purchase Intent of Genetically Modified Food: Based on the Perspectives of Product Knowledge, Perceived Benefits, Risk Reduction Strategies and Perceived Risk. Technoeconomics \& Management Research, 9: 45-52

Hawkins D. I. and D. L. Mothersbaugh 2012 Consumer Behavior: Building Marketing Strategy. McGraw-Hill Education, New York

Huang J. K. 2004 the Development of Genetically Modified Crops is in line with China's Interests. http://www.ahnw.gov. cn/2006nykj/show.asp?ContentID $=\{67091 \mathrm{D} 82-7 \mathrm{FB} 6-468 \mathrm{C}-$ 942D-CD9B64FBA9D7\}, Accessed on October 18, 2014

Kikulwe E. M., J. Wesseler and J. Falck-Zepeda 2011 Attitudes, Perceptions, and Trust. Insights from a Consumer Survey Regarding Genetically Modified Banana in Uganda. Appetite, 57: 401-413

Lang X. P. 2010 Behind the GM Rice. http //shehui. daqi. com/ article/2823572.html. Accessed on October 18, 2014

Laurent G. and J. N. Kapferer 1985 Measuring Consumer Involvement Profiles. Journal of Marketing Research, 22(1): 41-53

McComas K. A., J. C. Besley and J. Steinhardt 2014 Factors Influencing U.S. Consumer Support for Genetic Modification to Prevent Crop Disease. Appetite, 78C: 8-14

Ma L. and H. Y. Gu 2011 The Empirical Research on the Effect of the Information on the Genetically Modified Food and Labeling Policy on Consumer Preferences. Journal of Agrotechnical Economics, 9: 65-73

Nayga, R. M. Jr. 1996 Sociodemographic Influences on the Consumer Concern for Food Safety: the Case of Irradiation, Antibiotics, Hormones and Pesticides. Review of Agricultural Economics, 18(3): 467-475

Qi Z. H. and H. Zhou 2010 the Empirical Analysis on the Consumers' Awareness of Genetically Modified Food: A Case of the City of Wuhan. China Rural Survey, 6: 35-43

Quan S. W., Y. C. Zeng and Y. Y. Liu 2011 Consumer Perceived Risk and Risk Attitude towards the Brand Diary Products at 
Home and Abroad: Based on the Survey after the Melamine Scandal. China Rural Survey, 2: 2-15

Rodríguez-Entrena M., M. Salazar-Ordóñez and S. Sayadi 2013 Applying Partial Least Squares to Model Genetically Modified Food Purchase Intentions in Southern Spain Consumers. Food Policy, 40: 44-53

Steur H. D., X. Gellynck, S. Feng, P. Rutsaert and W. Verbeke 2012 Determinants of Willingness-to-Pay for GM Rice with Health Benefits in a High-Risk Region: Evidence from Experimental Auctions for Folate Biofortified Rice in China. Food Quality and Preference, 25(2): 87-94
Zhang Q. F. 2013 the Slow Development in Transgenic Technology Industry will be a Great Loss for China. http:// money.163.com/13/1020/17/9BL5S36N00254TI5.html. Accessed on October 18, 2014

Zhong F. N. and X. Chen 2008 Genetically Modified Food, Consumers' Purchasing Behavior and Market Share: A Study of Urban Residents' Oil Purchases in Supermarkets. China Economic Quarterly, 7(3): 1061-1078

Zhong F. N. and Y. L. Ding 2004 Consumer Awareness and Response to Genetically Modified Foods in Nanjing. China Rural Survey, 1: 22-27 